\title{
Work Optimization of the Production Staff when Implementing Technical Innovations
}

\author{
Mikhailov F.B. ${ }^{a}$ \\ Fakhrutdinova E.V. ${ }^{\text {b }}$ \\ Yagudin R.Kh.c \\ Mefodeva M.A. ${ }^{d}$ \\ a, b, d Kazan Federal University, Institute of Management, Economics and Finance, Kazan, 420008, Russia \\ c Republican Clinical Hospital, 420064, Kazan, Orenburg tract, 138, Russia
}

\section{Doi:10.5901/mjss.2015.v6n1s3p86}

\begin{abstract}
Technological innovations significantly affect the main characteristics of the labor process of the production staff. Thus, the production efficiency can be related to the increase of the labor intensity, which is associated with negative consequences both social and economic. Therefore, there is a complex optimization problem of labor activity based on labor efficiency, intensity, uniformity. The solution of this problem cause the task of selecting a method of estimating of the labor intensity and economic and mathematical modeling of the organization of labor processes according to the criteria of economic and social efficiency.
\end{abstract}

Keywords: personnel, innovations, productivity, labor intensity, optimization, efficiency.

\section{Introduction}

Technical innovation is to improve the production efficiency, as a rule for the release of new, more competitive products.

The variety of equipment used in the Russian production leads to the creation of unique technical systems.[1]

Therefore, there is a need to develop innovative organizational solutions, which on the one hand, would take into account the maintenance features and a condition for the effective functioning of the new equipment, and on the other the hand, the most important criteria for activation of the labor potential of the production staff. After all, the main characteristics of the labor potential and the worker's health tend to constant changes. As a result of such changes the labor potential of a person either increases or decreases in terms of the overall result of the evolution of the potential, since the dynamics of labor potential let in the possibility of presence of not the same vector actions of its constituent elements.

For example, an employee can actively develop their professional competence on the background of the deteriorating state of their physical and mental condition. [2]

\section{Method}

The study of organization problems of the labor process in the conditions of modern production is of the relevant value, including the optimization of the labor intensity of the production staff that is the least studied. [3] In terms of this problem, the optimization of the labor intensity means the elimination or, preferably, prevention of the inconsistencies between the physiological capabilities of the person and working conditions.

Until recently, the research on optimization of work intensity was limited to the area of the labor physiology, and the main attention was paid to the reduction of physical activity. The introduction of automated machines with the reduction of physical activity led to the increase in mental and psychic strain. Labor intensity of the operators of automated equipment has been determined primarily by construction and kinematic features of the equipment. Synchronization of the automated production eliminates the downtime of the machines according to the will of the operator. The value of the labor intensity as a factor of productivity is not only preserved, but even increased, since the production volume and quality depends on the accuracy of the operator actions, the reception of signals about the possible malfunction of the automated equipment and its adjustment. The reliability of service is sharply reduced with an excessive labor intensity of operators that leads to accidents or failures of the technical system with the risk of injury, as well as significant economic 
losses that can lead to substantial loss of economic benefits of innovation and that is especially dangerous, to their social rejection in the organization. [4] Therefore, the evaluation of the labor intensity on projects of the introduction of new technology seems to be the first step in the organization optimization process.

As our research shows, the labor intensity of semiautomatic operators depends mainly on the volume of stress in the process of fulfilling support operations (installation of the preform, transerence of the finished piece). In addition, the labor intensity of the operator affects the monotony, which is particularly high when working on semiautomatic machines.

The labor intensity of automatic equipment operators is determined by the size of the mental, psychic and emotional strain associated with the need to monitor the process and actions. When transferring from one machine to another, the content of work changes and the factors that have a dominant effect on its intensity. Relying on this conclusion, the algorithm for measuring the labor intensity, in our opinion, can be represented in the form of dependencies, each of which displays the function of the objective -intensity work while using one of the classes of equipment. Variable functions of the objective are the factors that have a dominant influence on the level of labor intensity. The labor intensity in each of the dependencies is represented as a product of factors that determine its value and has the following form:

$J 1=d s c M$,

where, $\mathrm{J} 1$ - labor intensity;

$d$ - mechanical work $(\mathrm{kg} / \mathrm{m})$;

$s$ - static work ( $\mathrm{kg} / \mathrm{sec})$;

$c$ - biomechanical work;

$M$ - monotony of work (a number of techniques in repetitive operations, the timing of the repetitive operations, c; the number of operations per hour).

he formula for the labor intensity of operators working on the machines is expressed as follows:

$J 2=\operatorname{tn} \vee m f$,

where, tn - the percentage time activity attention to the shift time;

$v-$ a number of signals to the action when controlling production process (on the shift);

$m$ - intellectual work according to expert rating.

As it is known, assessment factors of the work content, as well as its intensity have received a long-run appraisal and provide rather reliable information about the degree of manifestation of this or that factor in the labor process. In the following table we present a fragment of one of the widely-tested methods of work meaningfulness. [5]

Table 1. Quantitative assessment of comparative content of specific types of work

\begin{tabular}{|l|l|l|l|}
\hline \multirow{2}{*}{ Characteristics } & The number of points & 90 \\
\cline { 2 - 4 } & 10 & 50 & \multicolumn{2}{|l|}{$\begin{array}{l}\text { Autonomy (A) } \\
\text { 1. the ability to pre- } \\
\text { regulate the labor }\end{array}$} & $\begin{array}{l}\text { All transactions are made in } \\
\text { accordance with the } \\
\text { instructions }\end{array}$ & $\begin{array}{l}50 \% \text { of the operations are } \\
\text { performed by the } \\
\text { instructions }\end{array}$ & It is impossible to regulate \\
\hline $\begin{array}{l}\text { 2. the sequence of } \\
\text { operations }\end{array}$ & The same (90\%) & Can change for $50 \%$ & It is determined freely \\
\hline $\begin{array}{l}\text { 3. the choice of raw } \\
\text { materials }\end{array}$ & Absent & $\begin{array}{l}\text { Can reject raw materials } \\
\text { of poor quality with the } \\
\text { permission of the master }\end{array}$ & More independently select raw materials \\
\hline $\begin{array}{l}\text { 4. the connection with } \\
\text { the functional services }\end{array}$ & $\begin{array}{l}\text { Less than four types of } \\
\text { service }\end{array}$ & $\begin{array}{l}\text { More than eight types of } \\
\text { service }\end{array}$ & More than ten types of service \\
\hline $\begin{array}{l}\text { Interdependency (B) } \\
\text { 1. interdependence with } \\
\text { other employees }\end{array}$ & $\begin{array}{l}\text { The inability to leave the } \\
\text { workplace without } \\
\text { replacement even for an } \\
\text { hour }\end{array}$ & $\begin{array}{l}\text { The ability to leave the } \\
\text { workplace for a few hours }\end{array}$ & $\begin{array}{l}\text { The ability to leave the workplace for more } \\
\text { than a day }\end{array}$ \\
\hline $\begin{array}{l}\text { Responsibility (O) } \\
\text { 1. the possibility of } \\
\text { making important } \\
\text { decisions }\end{array}$ & $\begin{array}{l}\text { The absence of the } \\
\text { possibility to influence } \\
\text { production deliberately }\end{array}$ & $\begin{array}{l}\text { The correct (wrong) } \\
\text { decisions are not } \\
\text { immediately obvious }\end{array}$ & $\begin{array}{l}\text { The correct (wrong) decisions become } \\
\text { apparent after a long time. }\end{array}$ \\
\hline
\end{tabular}




\section{Results}

Conducted in the automotive industry, our research points to the possibility of the development of economic and mathematical optimization model of the labor process when introducing the new equipment. The task consists of the combination of characteristics of the labor process, i.e. such a combination, when they reach higher labor productivity by maintaining work efficiency of the operator. The isolated, local approach to the optimization of any of the characteristics of the labor process, including the labor intensity, without its interaction with other characteristics, will not lead to a constructive solution, i.e., the correct choice of means of improving work efficiency with its normal intensity. [6]

Figure 1 presents an optimization model of labor intensity taking into account the relationship peculiarities of the latter with the most important characteristics of the labor process when working on an automated equipment: productivity and monotony.

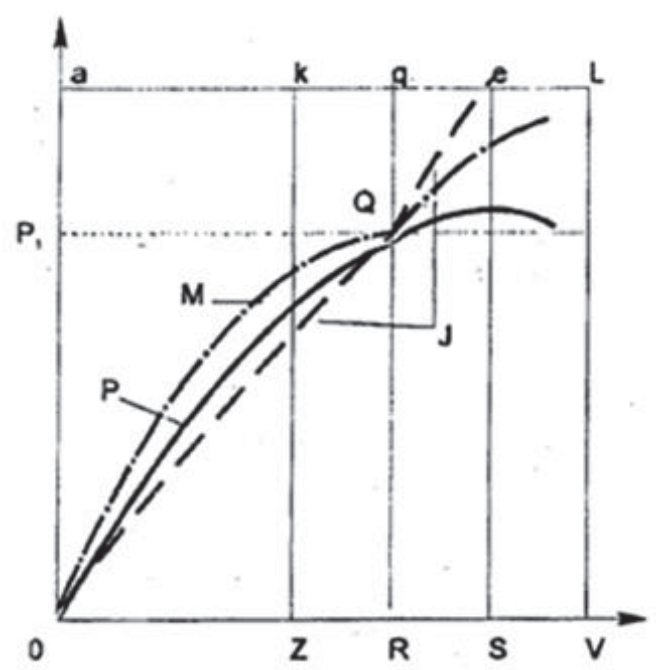

Fig.1. The version of the economic and mathematical model of process of work optimization with the introduction of automated machinery.

The model is built for a typical case, when the main characteristics of labor, namely productivity, intensity and monotony are almost predetermined by work schedule of the automated machinery in normal sanitary conditions. [7]

$P$ - operator's output, an item per shift;

$P 1$ - planned maximum operator's output at normal level of labor intensity, an item per shift;

$M$ - monotony of the work (the number of operations repeated an hour);

$J$ - labor intensity of the operator (in relative units - points).

Point Q characterizes the optimum of labor intensity. It corresponds to the achievement of the highest productivity at normal intensity and acceptable level of work monotony.

OaeS is the area of psychic and physiological abilities of the staff, within which labor costs are compensated by the body under normal conditions of their compensation;

ОакZ determines the zonal region of the labor processes, where the labor intensity, under equal conditions, below the normal level, with the exception of the period of mastering of new equipment.

Here there is a real reserve for productivity increasing due to its intensity. For operators of semi-automated machines it is possible to achieve it, for example, by reducing the automatic processing cycle, and for personnel involved in the local machines service, one can provide acceptable options of combining an engineer's job, the expansion of service area, the increasing the number of controlled machines. [8]

ZkqR and RqeS are regions that characterize the labor process, and that is similar in its characteristics to the optimum one. There one can see stable productivity, enabling staff to achieve high productivity results and to demonstrate their creative abilities. As for processes of work, that require a special accuracy, as well as on the stages of development of new equipment, it is preferable a mode of work corresponding to the area ZkqR. Labor productivity in this area is lower than in RqeS, however, this mode of operation allows the staff is more likely to prevent an extreme situation caused by equipment failures and emergency situations. An extreme labor process is defined in the SeLV area. 
Production at this level of labor intensity can be very high for a limited period, but then, due to the overworking, inevitably fall. The modeling of the work process in conjunction with local experimentation allows to choose such innovative organization solutions of the labor process when introducing technological innovations that give the best combination of the main characteristics of the labor process (productivity, intensity, monotony) in specific organizational and technical conditions for the automated production, that should ensure the growth of labor productivity with a high availability of staff, to preserve people's health.

It is important to note that the implementation of innovative activities in the process of technological innovation cannot be free from the restrictions and conditions for the achievement of social and economic efficiency of the system "a human - automation technology" as a whole. Here we mean the high cost of new equipment. So it is necessary to control the costs to maintain efficient operating conditions. We should assess the situation where the additional costs for tools replacing, and the repair of unique equipment may not be compensated by the profits achieved as a result of it. In this case, optimization is about finding a compromise solution about achieving both economic and social efficiency of the introduction of new equipment. Figure 2 shows the variety of relationships between the fundamental economic and social characteristics, caused by the choice of the operation mode of new equipment.

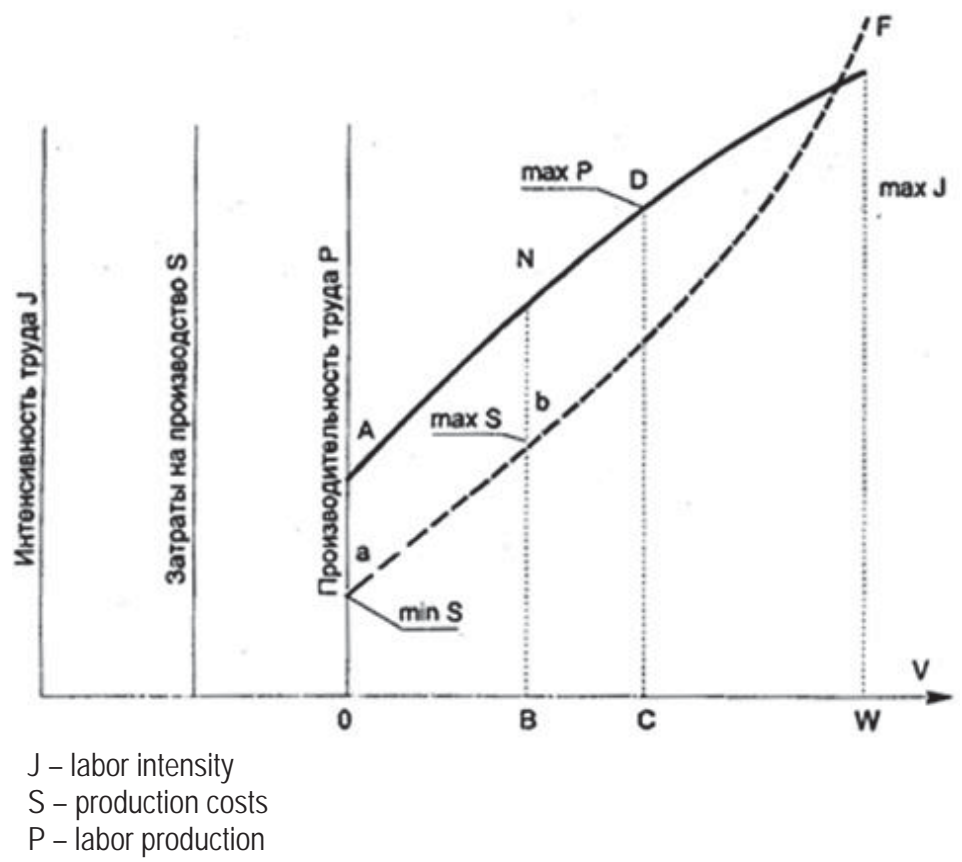

Fig. 2. Variants of the relationships between the fundamental economic and social characteristics of the operation of the new equipment depending on its operating mode.

References to the figure:

$V$ - speed of operation of the equipment;

$C$ - mode of operation at normal level of labor intensity and the corresponding high productivity;

A - mode with the maximum allowable cost production;

a - mode with the lowest costs production;

CDFW - area of operation modes, forbidden according to the following criteria:

j $>\max \mathrm{J}$

$\mathrm{S}>\max \mathrm{S}$;

OADC - the area of operation modes where the growth production costs outpaces the increase resultsdue to productivity gains.

Point $D$ corresponds to the maximum value of productivity $\max P$, excess of which is not valid as the labor intensity in this case will exceed physically normal level.

At the point in the BNDC area the economic effect of productivity growth will not exceed the extra cost of the tool wear and components and details . 
The coordinate origin here corresponds to the minimum value of the production cost min $S$. The optimal level of production costs corresponds to the point $\mathrm{a}$, and it should also be planned with the introduction of technological innovations for the cost assessment.

Under identical conditions, the choice of modes of operation in the area of DNBS is preferable in case when the value of the cost for the tools recovery takes a relatively lower value as a result of high qualification of the personnel involved with the implementation and new equipment service, the presence of good repair facilities that meet modern requirements.

Thus, dependences can be used effectively for particular decisions at the option of the rational integration of management and technological innovations in the modern automated production. The implementation of solutions to improve the efficiency of the innovation system "a human - new equipment" will be in each case specific because of the large diversity and automated equipment, and organizational conditions of production.

\section{References}

Fakhrutdinova, E., Kirshin, J., Kolesnikova, J., Salyakhov, E, The influence of cross-country Technological transfer on economic profit formation//Middle East Journal of Scientific Research 2013 (12), PP. 1632-1634

Fakhrutdinova, E., Karasik, E., Kolesnikova, J., Yagudin, R., Study of problems of population`s poverty of Russia//Mediterranean Journal of Social Sciences 20145 (18 spec. issue), pp. 139-144.

Scarborugh, $\mathrm{H}$ and Elias, J. Evaluating Human Capital, London, CiPD, 2001.

Bijker, Wiebe E., Of Bicycles, Bakelites, and Bulbs: Toward a Theory of Sociotechnical Change. Cambridge, MA: MiT Press, 1989

Back W, Productivity controls and Management. Albany, 1976

Purcell, J., Kinnie, K., Hutchinson S., Rayton, B and Smart, J. Understanding The People and Performance Link; Unlocking the black box. London, CiPD, 2003.

Law, John, and John Hassard. Actor Wetwork Theory and After. Oxford, UT; Blackewell Publishers, 1999

Fletcher, C. Routesto Improved performance. London, Institute of Personell and Development, 1993

Mayo, A. The Human Value of the Enterprise: Valuing people as assets-monitoring, measuring, managing. London, Nicholas Brealey, 2001.

Fitz-Bnk, J. The ROI of Human Capital: Measuring the economic Value of Employee performance, New-York, Amacom, 2000.

Safiullin M.R., Elstin L. A., Shakirova, A. J. 2012 Evaluation of business and economic activity as a short-term forecasting tool// Herald of the Russian Academy of Sciences (4), pp. 290-294 